\title{
Associations of Common Genetic Variants on IL-17 Genes and Carotid Intima-Media Thickness
}

\author{
Tzu-Wei Wu ${ }^{1}$, Chao-Liang Chou ${ }^{1,2}$, Yi-Cheng Chen ${ }^{1}$, Yue-Li Juang ${ }^{3}$ and Li-Yu Wang ${ }^{1,3}$ \\ Tzu-Wei Wu and Chao-Liang Chou contributed equally to this work.
}

${ }^{1}$ Department of Medicine, Mackay Medical College, New Taipei City, Taiwan

${ }^{2}$ Department of Neurology, Mackay Memorial Hospital, New Taipei City, Taiwan

${ }^{3}$ Institute of Biomedical Sciences, Mackay Medical College, New Taipei City, Taiwan

Aim: Atherosclerosis is a chronic inflammatory process of the arterial wall and carotid intima-media thickness (cIMT) is regarded as its early marker. Several members of the IL-17 family are involved in pro-inflammatory functions. The specific aim of the study was to explore the relationships of common genetic variants on $I L-17$ genes with cIMT thickening.

Methods: In the discovery stage, 146 SNPs on $11 I L-17$ genes were screened for their relationships with cIMT by a case-control study that enrolled 284 and 464 subjects who had thicker and normal cIMT, respectively. Findings were replicated by an independent case-control study that enrolled 282 subjects who had thicker cIMT and 282 age-sex-matched subjects who had normal cIMT.

Results: Among 134 eligible SNPs in the discovery study, only $I L-17 R C$ rs279545 was significantly correlated with cIMT $\left(p=6.9 \times 10^{-5}\right)$. The rs279545 and 2 nearby linked SNPs rs 55847610 and rs3846167 were included in the validation study. We found that the $r s 279545^{*} G, r s 55847610^{*} G$, and $r s 3846167^{*} C$ were correlated with significantly higher likelihoods of having thicker cIMT. The corresponding multivariate-adjusted ORs were 1.462 (95\% CI: 1.055-2.027), 1.481 (95\% CI: 1.090-2.013), and 1.589 (95\% CI: 1.147-2.200), respectively. Analyses of rs279545-rs55847610 haplotypes showed that the multivariate-adjusted OR for A-A haplotype was significantly decreased $(\mathrm{OR}=0.665,95 \% \mathrm{CI}: 0.487-0.908)$ and for $\mathrm{G}-\mathrm{G}$ haplotype was significantly increased $(\mathrm{OR}=1.539,95 \% \mathrm{CI}: 1.097-2.161)$.

Conclusions: We first correlated cIMT, a preclinical clinical cardiovascular marker, with IL-17RC, the key molecule in the IL-17 signaling pathway. Our results indicated that IL-17RC may play critical role in the development of atherosclerotic diseases.

Key words: Common carotid intima-media thickness, Single nucleotide polymorphism, IL-17, Genetic association study, Community-based study

\section{Introduction}

Atherosclerosis is one of the major pathologies of cardiovascular diseases (CVDs) ${ }^{1)}$. It more frequently occurs in aged subjects, accordingly, the global public health impacts of atherosclerosis will continuously increase with the elongation of life expectancy ${ }^{2)}$. To alleviate the impacts attributable to atherosclerosis, it is essential to identify biomarkers that present at the earlier pathogenic process and have well predictive ability simultaneously and to explore its determinants that will be served as the target of prevention and control.

Among several parameters that had been tested

Address for correspondence: Li-Yu Wang, Department of Medicine, Mackay Medical College, New Taipei City, Taiwan. No. 46, Sec. 3, Jhong-Jheng Rd., San-Jhih District, New Taipei City, Taiwan. E-mail: yannbo@mmc.edu.tw

Received: February 10, 2018 Accepted for publication: March 13, 2018

Copyright@2018 Japan Atherosclerosis Society

This article is distributed under the terms of the latest version of CC BY-NC-SA defined by the Creative Commons Attribution License. 
to detect changes in the blood vessel structures and their ability to predict the most deleterious clinical manifestations myocardial infarction and stroke, carotid intima-media thickness (cIMT) can be detected easily and non-invasively using B-mode carotid ultrasound ${ }^{3,4)}$. In addition to myocardial infarction and stroke ${ }^{5-7)}$, thicker cIMT has been strongly correlated with cognitive impairments ${ }^{8-9)}$. Currently, cIMT measurement is wildly used to assess the vascular health status of an individual and thicker cIMT is regarded as an intermediate phenotype of atherosclerosis.

Atherosclerosis is a chronic inflammatory process of the arterial wall ${ }^{10)}$. Recently, a new $T$ helper cell subset that secrets signature cytokine IL-17 was identified $^{11)}$. Several members of the IL-17 family are involved in pro-inflammatory functions ${ }^{12}$. The IL-17 family induces downstream responses through binding with cell surface receptors, e.g., IL-17RC is critical to the binding of IL-17A and IL-17F ${ }^{13)}$. Additionally, previous twin studies showed that significant proportions of cIMT variations could be explained by genetic factors ${ }^{14-16)}$. It is reasonable to hypothesize that genetic variants on these $I L-17$-related genes may also contribute to cIMT thickening. Accordingly, the specific aim of the study was to explore the relationships between common genetic variants in IL-17-related genes and cIMT.

\section{Materials and Methods}

Study Design and Study Subjects

We used two case-control studies to explore the influences of common genetic variants on $I L-17$ genes with cIMT. The study subjects of the discovery study were from a community-based cohort enrolled by the Mitochondria-Aging in Northern Taiwan (MAGNET) study ${ }^{17)}$. From September 2010 to May 2012, 1607 residents aged 40-74 years were enrolled. Twentyseven subjects were excluded due to the lack of good quality of recorded carotid ultrasound images, and another 40 subjects who had ever been diagnosed with coronary artery diseases and received cardiac catheterization and cardiovascular stent were also excluded, leaving a total of 1539 middle-aged and elderly participants in the MAGNET study. The $75^{\text {th }}$ percentile of the distribution of the mean fall-wall IMT of common carotid arteries (CCA) was $0.70 \mathrm{~mm}^{18)}$. We randomly selected a sample of 284 subjects who had a mean CCA IMT $\geq 0.70 \mathrm{~mm}$ as the cases and selected a sample of 464 subjects who had a mean CCA IMT $<0.70 \mathrm{~mm}$ as the controls.

The study subjects of the validation study were selected from an ongoing community-based cohort enrolled residents aged 40-74 years. Among 1198 voluntarily participants who enrolled during May 2014 and Dec 2016, 1164 of them had good quality of recorded carotid ultrasound images and had no CVD history. We used a 1:1 frequency-matched case-control study design and selected a random sample of 282 subjects from those who had thicker cIMT as the case group. Based on the age (40-49, 50-59, and $\geq 60$ years) and sex distribution of the cases, we performed stratified random sampling and selected a total of 282 subjects who had normal cIMT as the controls.

All participants of the two community-based studies voluntarily provided informed consent. The studies complied with the 1975 Helsinki Declaration on ethics in medical research and was reviewed and approved by the Institution Review Board of Mackay Memorial Hospital (14MMHIS075).

Measurements of Anthropometric and Cardiovascullar Profiles

Measurements of anthropometric had been described previously ${ }^{17)}$. In short, body weight and height were measured by a digital system (BW-2200; NAGATA Scale Co. Ltd., Tainan, Taiwan). Waist circumference (WC) was measured at the level of middistance between the bottom of the rib cage and the top of the iliac crest. Body mass index (BMI) was calculated as (body weight) $/$ (body height $)^{2}\left(\mathrm{~kg} / \mathrm{m}^{2}\right)$. Blood pressure was measured three times by a digital system (UDEX-Twin; ELK Co., Daejon, Korea) in the morning after $10 \mathrm{~min}$ of rest. The averages of three measurements of systolic blood pressure (SBP) and diastolic blood pressure (DBP) were used for analyses.

A $10 \mathrm{ml}$ of fasting venous blood samples were collected for cardiovascular profile analyses. The levels of total cholesterol, high-density lipoprotein cholesterol (HDL-C), low-density lipoprotein cholesterol (LDL-C), fasting triglycerides (FTG), and fasting plasma glucose (FPG) were determined by an autoanalyzer (Toshiba TBA c16000; Toshiba Medical System, Holliston, MA, USA) with commercial kits (Denka Seiken, Tokyo, Japan). In this study, hypertension was defined as SBP $\geq 140 \mathrm{mmHg}, \mathrm{DBP} \geq 90$ $\mathrm{mmHg}$, or a history of taking antihypertensive medications. Dyslipidemia was defined as total cholesterol $\geq 240$, LDL-C $\geq 160$, or HDL-C $<40 \mathrm{mg} / \mathrm{dL}$ or the use of lipid lowering medicines. Diabetes mellitus (DM) was defined as FPG $\geq 126 \mathrm{mg} / \mathrm{dL}$ or the use of hypoglycemic agents. Cigarette smoking was defined as having smoked cigarette for at least 4 days per week and lasting for 3 months or more. 


\section{The cIMT Measurement}

The measurement of cIMT was performed according to the protocol recommended by the American Society of Echocardiography ${ }^{19)}$ and as described previously ${ }^{18)}$. In short, two experienced technicians, who were blind to patients' clinical characteristics, obtained and digitally stored both left and right CCA images by using high-resolution B-mode ultrasonography systems (GE Healthcare Vivid 7 and Vivid E9; General Electric Company, Milwaukee, USA), equipped with a multi-frequency linear array transducer. A well-trained technician measured the far wall IMTs blindly by using automatic contouring software (GE Healthcare EchoPAC version 112.0.2; General Electric-Vingmed, Horten, Norway). The IMT was defined as the distance between the lumen-intima and media-adventitia interfaces and included plaques. The average, minimum, and maximum IMTs of the distal $1-2 \mathrm{~cm}$ of the left and right CCA were recorded. Mean cIMT was calculated as the mean of the left and right average IMTs and was used for statistical analyses. Our previous study showed that the measurement of cIMT was highly reliable, with intra-class correlation coefficient $r$ greater than $0.97^{18)}$.

\section{SNP Selections}

In the discovery study, we used a plate that was designed for the Han Chinese population to screen the relationships of common genetic variants on 11 IL-17-related genes with cIMT. There were 146 SNPs within $+/-25 \mathrm{~Kb}$ of the IL-17A $(n=14), I L-17 B(n=$ 11), IL-17C $(n=3), I L-17 D(n=4), I L-17 E(n=15)$, $I L-17 F(n=18), I L-17 R A(n=25), I L-17 R B(n=20)$, $I L-17 R C(n=2), I L-17 R D(n=28)$, and IL-17RE $(n=$ 7) genes. The eligibility of SNPs for association analyses were a call rate $>95 \%$, a $p$-value of Hardy-Weinberg Equilibrium test in the controls $>0.001$, and a minor allele frequency $>5 \%$. For SNPs with a p-value less than the pre-set significance level, calculated as $0.05 / 146=3.4 \times 10^{-4}$, were regarded as candidate genetic markers and were subjected to validation study.

In addition to the candidate SNP, SNPs that are highly linked with candidate genetic variants and may influence expression and regulation of the associated $I L-17$ genes were considered for the validation study. The linkage disequilibrium (LD) data in the 1000 Human Genome Project Phase 3-Southern Han Chinese ${ }^{20)}$ were retrieved by using the Ensemble Genome Browser ${ }^{21)}$. The cut-off LD $\left(r^{2}\right)$ value of linkage was set at 0.80 .

\section{Genotyping}

Genomic DNA of each subject was extracted from EDTA-containing whole blood samples by a semi-automated extraction system Smart LabAssist (Taiwan Advanced Nanotech Inc., Tau-Yuan County, Taiwan) with TANBead Blood DNA plate (Taiwan Advanced Nanotech Inc.).

We used the Axiom ${ }^{\circledR}$ CHB 1 Array Plate (Affymetrix Ltd, Santa Clara, CA, USA) Affymetrix Ltd) and the Sequenom iPLEX MassARRAY system (Sequenom, San Diego, CA) to determine the genotypes of study subjects of the discovery and validation studies, respectively. All genotyping were performed by the National Center for Genome Medicine, Academic Sinica, Taiwan.

\section{Statistical Analyses}

In the study, we used the student's $t$ and the chisquare tests to compare whether there were significant differences in the anthropometric and laboratory measurements between cases and controls. The chi-square test was also used to compare whether there were significant differences in the frequency distributions of genotypes among groups. The $\mathrm{Z}$ test was used to compare the significance of relative frequencies of minor alleles between case and control groups.

The relationships with thicker cIMT for common genetic variants on $I L-17$ genes were assessed by the additive genotypic effect model. Anthropometric and clinical factors significantly correlated with cIMT were subject to multivariate logistic regression. Assessment of pairwise LD and estimation of haplotype frequencies were performed by Haploview 4.2 software $^{22)}$. Adjusted odds ratio (OR) and 95\% confidence interval (CI) were calculated by models with and without clinical markers. All statistical analyses were performed using SAS 9.4 (SAS Institute Inc., Cary, NC, USA).

\section{Results}

\section{Clinical Characteristics of Study Subjects}

In the discovery study, cases had significantly higher means of all, except for HDL-C, anthropometric and laboratory measurements than those of the controls (Table 1). The mean level of HDL-C and the proportion of female subjects were significantly lower in the cases than that of the controls. As compared with the controls, the prevalence rates of dyslipidemia, hypertension, and DM were significantly higher in the case group. In the validation study, similar differences in all, except for age, sex, and DM, anthropometric and laboratory measurements between cases and controls were observed.

Among 146 screened SNPs, 12 of them were excluded due to inadequate call rate $(n=4)$, a minor 
Table 1. Clinical characteristics of subjects of the discovery and validation studies

\begin{tabular}{|c|c|c|c|c|c|c|c|c|}
\hline \multirow[b]{2}{*}{ Variable } & \multicolumn{4}{|c|}{ Discovery study } & \multicolumn{4}{|c|}{ Validation study } \\
\hline & Mean & SD & Mean & SD & Mean & SD & Mean & SD \\
\hline Age at enrollment (years) & 52.6 & 8.7 & 58.9 & 8.8 & 58.0 & 8.5 & 58.5 & 8.5 \\
\hline BMI $\left(\mathrm{kg} / \mathrm{m}^{2}\right)$ & 24.1 & 3.5 & 25.9 & 3.3 & 24.4 & 3.6 & 25.7 & 3.2 \\
\hline Waist-to-hip ratio (\%) & 84.9 & 7.4 & 88.0 & 6.4 & 86.7 & 7.1 & 86.9 & 6.1 \\
\hline $\mathrm{SBP}(\mathrm{mm} \mathrm{Hg})$ & 126.1 & 19.5 & 135.0 & 17.7 & 128.6 & 19.5 & 135.2 & 18.2 \\
\hline DBP (mm Hg) & 78.6 & 13.3 & 82.6 & 13.4 & 79.7 & 14.6 & 82.3 & 13.8 \\
\hline Total cholesterol (mg/dL) & 205.7 & 36.0 & 216.2 & 42.6 & 208.9 & 38.3 & 213.7 & 37.9 \\
\hline LDL-C (mg/dL) & 121.4 & 33.2 & 133.8 & 35.8 & 123.2 & 35.5 & 131.6 & 31.3 \\
\hline Fasting plasma glucose (mg/dL) & $n$ & $\%$ & $n$ & $\%$ & $n$ & $\%$ & $n$ & $\%$ \\
\hline Male sex & 213 & 45.9 & 157 & 55.3 & 143 & 50.0 & 143 & 50.0 \\
\hline Cigarette smoking & 74 & 16.1 & 52 & 18.6 & 38 & 13.5 & 48 & 17.0 \\
\hline Dyslipidemia & 124 & 26.7 & 133 & 46.8 & 90 & 31.9 & 121 & 42.9 \\
\hline Diabetes mellitus & 25 & 5.4 & 39 & 13.7 & 29 & 10.3 & 34 & 12.1 \\
\hline Hypertension & 134 & 28.9 & 134 & 47.4 & 93 & 33.0 & 128 & 45.4 \\
\hline
\end{tabular}

allele frequency of $<0.05(n=3)$, and significant deviation from Hardy-Weinberg equilibrium ( $P$ value of $\left.<1 \times 10^{-3} ; n=5\right)$. Among the 134 eligible SNPs for the association analyses, only rs 279545 passed the preset significance level of the discovery study and was regarded as candidate genetic marker (Supplementary Table 1).

The LD data of the Southern Han Chinese shows that 5 SNPs, including rs3774207, rs55847610, rs59465469, rs55847233, and rs3846167, fitted to the inclusion criteria of the validation study. The rs3774207, rs55847610, rs59465469, and rs55847233 are of the same complete LD block ${ }^{20)}$, and among them, rs55847610 is the most suitable for the genotyping platform. Therefore, rs279545, rs55847610, and rs3846167 were included in the validation study (Supplementary Table 2).

The test statistics showed that the distributions of the rs279545, rs55847610 and rs3846167 genotypes were significantly different between the case and control groups (Table 2). The minor alleles, i.e., rs $279545^{*} G, r s 55847610^{*} G$, and $r s 3846167^{*} C$, were correlated with higher likelihoods of having thicker cIMT. Further adjustment for age, sex, and traditional CVD risk factors, the estimated ORs of having thicker cIMT changed slightly. The corresponding multivari- ate-adjusted ORs were 1.462 (95\% CI: 1.055-2.027), 1.481 (95\% CI: $1.090-2.013)$, and 1.589 (95\% CI: $1.147-2.200)$, respectively.

$\mathrm{LD}$ analyses showed that the value of $\mathrm{D}$ prime between rs279545 and rs55847610 was 0.96 and was 0.81 for rs 279545 with rs3846167. The rs 279545 and rs55847610 were grouped as a LD block. We subsequently analyzed the relationship of rs279545rs55847610 haplotype with the risk of thicker cIMT (Table 3). The multivariate-adjusted OR was significantly decreased for A-A haplotype (OR $=0.665,95 \%$ CI: $0.487-0.908 ; p=0.010)$ and significantly increased for $\mathrm{G}-\mathrm{G}$ haplotype $(\mathrm{OR}=1.539,95 \% \mathrm{CI}$ : $1.097-2.161 ; p=0.013)$.

\section{Discussion}

In the present study, we first identified rs279545 of the $I L-17 R C$ gene as a promising genetic marker of cIMT thickening and confirmed the finding by subsequent validation study. After adjustment for traditional CVD risk factors, OR of having thicker cIMT for the rs279545-G allele remained significantly increased. In addition to rs 279545 , two closely linked SNPs rs55847610 and rs3846167 also demonstrating significant correlations with cIMT thickening, which strengthen the validity of ours findings. To our knowl- 
Table 2. Association analyses for 3 candidate SNPs with thicker carotid IMT

\begin{tabular}{|c|c|c|c|c|c|c|c|c|c|}
\hline \multirow[b]{2}{*}{ SNP } & \multirow{2}{*}{$\begin{array}{l}\text { Allele } \\
\text { A/B }{ }^{1}\end{array}$} & \multicolumn{2}{|c|}{ Thicker cIMT } & \multicolumn{2}{|c|}{ Normal cIMT } & \multirow[b]{2}{*}{$\mathrm{P}_{\mathrm{GT}}$} & \multirow[b]{2}{*}{$P_{T R}$} & \multirow{2}{*}{$\begin{array}{c}\text { Crude OR } \\
\text { OR }(95 \% \text { CI) }\end{array}$} & \multirow{2}{*}{$\begin{array}{l}\text { Adjusted OR }{ }^{2} \\
\text { OR }(95 \% \mathrm{CI})\end{array}$} \\
\hline & & $\mathrm{B} \%$ & $\mathrm{AA} / \mathrm{AB} / \mathrm{BB}$ & $\mathrm{B} \%$ & $\mathrm{AA} / \mathrm{AB} / \mathrm{BB}$ & & & & \\
\hline \multicolumn{10}{|c|}{ Discovery study } \\
\hline rs279545 & $\mathrm{A} / \mathrm{G}$ & 22.9 & $172 / 94 / 18$ & 14.8 & $333 / 125 / 6$ & $5.7 \times 10^{-5}$ & $6.9 \times 10^{-5}$ & $1.716^{* *}(1.305-2.256)$ & $1.631^{* *}(1.201-2.216)$ \\
\hline \multicolumn{10}{|c|}{ Validation study } \\
\hline rs279545 & $\mathrm{A} / \mathrm{G}$ & 20.2 & $185 / 80 / 17$ & 13.5 & $209 / 70 / 3$ & 0.003 & 0.003 & $1.595^{* *}(1.166-2.182)$ & $1.462^{*}(1.055-2.027)$ \\
\hline rs55847610 & $\mathrm{A} / \mathrm{G}$ & 23.2 & $171 / 91 / 20$ & 16.0 & $198 / 78 / 6$ & 0.005 & 0.003 & $1.565^{* *}(1.165-2.102)$ & $1.481^{*}(1.090-2.013)$ \\
\hline rs3846167 & $\mathrm{T} / \mathrm{C}$ & 20.2 & $185 / 77 / 18$ & 12.9 & $211 / 64 / 4$ & 0.003 & 0.002 & $1.643^{* *}(1.201-2.249)$ & $1.589^{*}(1.147-2.200)$ \\
\hline
\end{tabular}

${ }^{1}$, Allele A/B, major/minor alleles.

${ }^{2}$, OR were adjusted for age, sex, SBP, LDL-C, BMI, and cigarette smoking.

Note: cIMT, carotid intima-media thickness; CI, confidence interval; OR, odds ratio; PGT, $p$-value for the Chi-square test of genotype distribution between subjects who had thicker and normal cIMT; PтR: $p$-value for the additive genotypic model.

*, $0.005<P<0.05$; **, $P<0.005$.

Table 3. Association analyses for rs279545-rs55847610 haplotypes with thicker carotid IMT

\begin{tabular}{lcccc}
\hline $\begin{array}{l}\text { rs279545-rs55847610 } \\
\text { haplotype }\end{array}$ & $\begin{array}{c}\text { Controls } \\
2 \mathrm{n}(\%)\end{array}$ & $\begin{array}{c}\text { Cases } \\
2 \mathrm{n}(\%)\end{array}$ & $\begin{array}{c}\text { Crude } \\
\text { OR }(95 \% \mathrm{CI})\end{array}$ & $\begin{array}{c}\text { Multivariate-adjusted } \\
\text { OR }^{1}(95 \% \mathrm{CI})\end{array}$ \\
\hline A-A & $475(84.2)$ & $433(76.8)$ & $0.619^{* *}(0.459-0.835)$ & $0.665^{*}(0.487-0.908)$ \\
G-G & $71(12.6)$ & $108(19.1)$ & $1.645^{* *}(1.188-2.277)$ & $1.539^{*}(1.097-2.161)$ \\
A-G & $18(3.2)$ & $23(4.1)$ & $1.290 \quad(0.688-2.417)$ & $1.214(0.631-2.335)$ \\
\hline
\end{tabular}

${ }^{1}$, OR were adjusted for age, sex, SBP, LDL-C, BMI, and cigarette smoking.

Note: cIMT, carotid intima-media thickness; CI, confidence interval; OR, odds ratio.

*, $0.005<P<0.05$; ** $P<0.005$.

edge, there was no report correlated genetic polymorphism of $I L-17 R C$ with a preclinical CVD marker. Our findings provided potential pathophysiological targets and clinical biomarkers for CVD treatments and predictions.

The indexed SNP rs279545 is located on the genic region of $I L-17 R C$ and is a non-coding transcript variant ${ }^{20)}$. To date, there were only 2 published reports about its putative functions. The rs279545 was the lead SNP that linked with local adaptation for eastern Asians ${ }^{23)}$ and was involved in the actin cytoskeleton pathway showing significant association with basal cell carcinoma ${ }^{24)}$. To explore possible function related to rs 279545 polymorphism, we searched the Taiwan Biobank to identify variants that result in functional change and has a minor allele frequency $>$ $3 \%$ in the $I L-17 R C$. We found only one missense SNP rs708567 fits the criteria ${ }^{25)}$. However, LD data of the Southern Han Chinese showed that this variant was not linked with the rs 279545 polymorphism but in complete LD with the rs279590 polymorphism ${ }^{20}$. Notably, the discovery study did not correlate rs279590 polymorphism with cIMT (Supplementary Table 1). Accordingly, the rs708567 polymorphism was unlikely a genetic marker for cIMT thickening. The role of the rs279545 polymorphism in the regulation and expression of IL-17RC waits for exploration.

Although there was no report exploring the effect of IL-17RC on atherosclerosis, a few human studies had explored the atherogenic effects of IL-17A, the ligand of IL-17RC. Initially, Li et al. (2005) assayed the IL-17 levels in the ischemic hemisphere of the human brain by an immunochemistry method ${ }^{26)}$. They found that IL-17 levels were elevated in the ischemic hemispheres of human brains and peaked at days 3-5 after brain ischemia. Furthermore, only very few IL-17-positive cells were observed in the opposite normal hemispheres of human brains ${ }^{26)}$. Similarly, several research groups observed IL-17A were expressed in human atherosclerotic lesions ${ }^{27-31)}$ and correlated the IL-17A expression levels with the vulnerability of atherosclerotic lesions ${ }^{28,29)}$. On the contrarily, one study reported that IL-17A expression was associated with more stable plaque phenotype rather than macrophage rich plaque areas ${ }^{32)}$.

In addition to IL-17 expression studies, there were studies compared the frequency of Th17 cells and levels of circulating IL-17 between patients with 
atherosclerotic diseases and controls. Most of flow cytometric studies showed that Th17 frequency in peripheral blood, either alone or in relation to T-cell count, was elevated in unstable or more advanced ath-

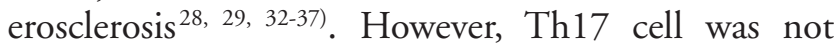
found in atherosclerotic tissues ${ }^{38)}$ and as compared with patients with acute myocardial infarction, the frequency of Th17 cells was significantly higher in patients with stable angina ${ }^{39)}$. Similarly, studies of serum or plasma levels of circulating IL-17A and severity or vulnerability of atherosclerosis showed inconsistent results. Most of studies had shown higher levels of circulating IL-17A in subjects with unstable or more advanced plaques ${ }^{31-36)}$. Unexpectedly, a prospective, multicenter study that enrolled acute ST-elevation and non-ST-elevation MI patients found that lower serum IL17 levels correlated with significantly higher risks of all-cause mortality and recurrent $\mathrm{MI}^{40)}$.

Collectively, some human studies suggested that IL-17 may promote the development of atherosclerosis while others pointed to IL-17 as an anti-atherogenic factor. Similarly, studies of isolated cells and animals demonstrated inconsistent findings ${ }^{41,42)}$. The inconsistent findings of different types of studies implicate that the involvement of IL-17 in atherosclerosis is complex. Due to the IL-17 signaling depend on the binding of IL-17s with cell surface receptors IL-17Rs, attempt to explore the effects of IL-17RC variants may help to clarify those discrepancies. Our findings provide a notch for further research.

There were potential limitations of the study. Our pretest showed that high proportion of subjects affected with hyperlipidemia, DM, and hypertension were not able to recall the date of diagnosis and provide information associated with treatments. Therefore, we did not collect these data and were not able to assess the effects of treatments on cIMT in the study. Theoretically, genotypes are not correlated with receiving treatment or not, accordingly, our findings were unlikely results of confounding. Additionally, all study subjects in the discovery and validation studies were restricted to Han Chinese, which may limit the external validity of the study.

In conclusion, we were first to successfully correlate cIMT, a preclinical clinical CVD marker, with IL$17 \mathrm{RC}$, the key molecule in the IL-17 signaling pathway. Our results indicated that IL-17RC may play critical role in the development of atherosclerotic diseases.

\section{Acknowledgement of Grant Support}

This work was supported by the Ministry of Science and Technology of Taiwan (grant number MOST
104-2314-B-715-002-MY3), Mackay Medical College (1041B15 \& 1051B15), and the Wang Jhan-Yang Public Charitable Trust Fund (WJY 2016-HR-01 \& WJY 2017-HR-01). The funding agencies played no role in the research. We thank the staffs in the district offices of Sanzhi District and Tamsui District, New Taipei City, for their administrative supports.

\section{Conflict of Interest Statement}

The authors declare no conflict of interest.

\section{References}

1) Hansson GK: Inflammation, atherosclerosis, and coronary artery disease. N Engl J Med, 2005; 352: 1685-1695

2) Mathers CD, Loncar D: Projections of global mortality and burden of disease from 2002 to 2030. PLoS Med, 2006; 3: e442

3) Nezu T, Hosomi N, Aoki S, Matsumoto M: Carotid intima-media thickness for atherosclerosis. J Atheroscler Thromb, 2016; 23: 18-31

4) Pignoli P, Tremoli E, Poli A, Oreste P, Paoletti R: Intimal plus medial thickness of the arterial wall: a direct measurement with ultrasound imaging. Circulation, 1986; 74: 1399-1406

5) Bots ML, Hoes AW, Koudstaal PJ, Hofman A, Grobbee DE: Common carotid intima-media thickness and risk of stroke and myocardial infarction: the Rotterdam Study. Circulation, 1997; 96: 1432-1437

6) Chambless LE, Heiss G, Folsom AR, Rosamond W, Szklo M, Sharrett AR, Clegg LX: Association of coronary heart disease incidence with carotid arterial wall thickness and major risk factors: the Atherosclerosis Risk in Communities (ARIC) Study, 1987-1993. Am J Epidemiol, 1997; 146: 483-494

7) O’Leary DH, Polak JF, Kronmal RA, Manolio TA, Burke GL, Wolfson SK Jr: Carotid-artery intima and media thickness as a risk factor for myocardial infarction and stroke in older adults. Cardiovascular Health Study Collaborative Research Group. N Engl J Med, 1999; 340: $14-22$

8) Komulainen P, Kivipelto M, Lakka TA, Hassinen M, Helkala EL, Patja K, Nissinen A, Rauramaa R: Carotid intima-media thickness and cognitive function in elderly women: a population-based study. Neuroepidemiology, 2007; 28: 207-213

9) Wendell CR, Zonderman AB, Metter EJ, Najjar SS, Waldstein SR: Carotid intimal medial thickness predicts cognitive decline among adults without clinical vascular disease. Stroke, 2009; 40: 3180-3185

10) Ross R: Atherosclerosis--an inflammatory disease. N Engl J Med, 1999; 340: 115-126

11) Iwakura $Y$, Ishigame $H$, Saijo $S$, Nakae S: Functional specialization of interleukin-17 family members. Immunity, 2011; 34: 149-162

12) Reynolds JM, Angkasekwinai P, Dong C: IL-17 family member cytokines: regulation and function in innate immunity. Cytokine Growth Factor Rev, 2010; 21: 413- 
423

13) Ho AW, Gaffen SL: IL-17RC: a partner in IL-17 signaling and beyond. Semin Immunopathol, 2010; 32: 33-42

14) Lee K, Sung J, Lee SC, Park SW, Kim YS, Lee JY, Ebrahim S, Song YM: Segment-specific carotid intima-media thickness and cardiovascular risk factors in Koreans: the Healthy Twin Study. Eur J Prev Cardiol, 2012; 19: 11611172

15) Zhao J, Cheema FA, Bremner JD, Goldberg J, Su S, Snieder H, Maisano C, Jones L, Javed F, Murrah N, Le NA, Vaccarino V: Heritability of carotid intima-media thickness: a twin study. Atherosclerosis, 2008; 197: 814-820

16) Medda E, Fagnani C, Schillaci G, Tarnoki AD, Tarnoki DL, Baracchini C, Meneghetti G, Fanelli F, Alaeddin A, Pucci G, Alviti S, Cotichini R, Brescianini S, Boatta E, Lucatelli P, Nisticò L, Penna L, Salemi M, Toccaceli V, Zini C, Garami Z, Stazi MA: Heritability of arterial stiffness and carotid intima-media thickness: an Italian twin study. Nutr Metab Cardiovasc Dis, 2014; 24: 511-517

17) Wu TW, Chan HL, Hung CL, Lu IJ, Wang SD, Wang SW, Wu YJ, Wang LY, Yeh HI, Wei YH; MAGNET Study Investigator: Differential patterns of effects of age and sex on metabolic syndrome in Taiwan: implication for the inadequate internal consistency of the current criteria. Diabetes Res Clin Pract, 2014; 105: 239-244

18) Wu TW, Hung CL, Liu CC, Wu YJ, Wang LY, Yeh HI: Associations of cardiovascular risk factors with carotid intima-media thickness in middle-age adults and elders. J Atheroscler Thromb, 2017; 24: 677-686

19) Stein JH, Korcarz CE, Hurst RT, Lonn E, Kendall CB, Mohler ER, Najjar SS, Rembold CM, Post WS; American Society of Echocardiography Carotid Intima-Media Thickness Task Force: Use of carotid ultrasound to identify subclinical vascular disease and evaluate cardiovascular disease risk: a consensus statement from the American Society of Echocardiography Carotid Intima-Media Thickness Task Force. Endorsed by the Society for Vascular Medicine. J Am Soc Echocardiogr, 2008; 21: 93-111

20) Yates A, Akanni W, Amode MR, Barrell D, Billis K, Carvalho-Silva D, Cummins C, Clapham P, Fitzgerald S, Gil L, Girón CG, Gordon L, Hourlier T, Hunt SE, Janacek SH, Johnson N, Juettemann T, Keenan S, Lavidas I, Martin FJ, Maurel T, McLaren W, Murphy DN, Nag R, Nuhn M, Parker A, Patricio M, Pignatelli M, Rahtz M, Riat HS, Sheppard D, Taylor K, Thormann A, Vullo A, Wilder SP, Zadissa A, Birney E, Harrow J, Muffato M, Perry E, Ruffier M, Spudich G, Trevanion SJ, Cunningham F, Aken BL, Zerbino DR, Flicek P: Ensembl 2016. Nucleic Acids Res, 2016; 44: D710-6

21) Ensemble Genome Browser: The Ensemble Genome Browser 86. http://asia.ensembl.org/Homo_sapiens/Info/ Index. Accessed Dec 2016

22) Barrett JC, Fry B, Maller J, Daly MJ: Haploview: analysis and visualization of LD and haplotype maps. Bioinformatics, 2005; 21: 263-265

23) Pickrell JK, Coop G, Novembre J, Kudaravalli S, Li JZ, Absher D, Srinivasan BS, Barsh GS, Myers RM, Feldman MW, Pritchard JK: Signals of recent positive selection in a worldwide sample of human populations. Genome Res, 2009; 19: 826-837

24) Li X, Liang L, De Vivo I, Tang JY, Han J: Pathway analy- sis of expression-related SNPs on genome-wide association study of basal cell carcinoma. Oncotarget, 2016; 7 : 36885-36895

25) Taiwan Biobank. Website: https://taiwanview.twbiobank. org.tw/index. Accessed at Aug 2017

26) Li GZ, Zhong D, Yang LM, Sun B, Zhong ZH, Yin YH, Cheng J, Yan BB, Li HL: Expression of interleukin-17 in ischemic brain tissue. Scand J Immunol, 2005; 62: 481486

27) Eid RE, Rao DA, Zhou J, Lo SF, Ranjbaran H, Gallo A, Sokol SI, Pfau S, Pober JS, Tellides G: Interleukin-17 and interferon-gamma are produced concomitantly by human coronary artery-infiltrating $\mathrm{T}$ cells and act synergistically on vascular smooth muscle cells. Circulation, 2009; 119: 1424-1432

28) Oliveira RT, Silva RM, Teo FH, Mineiro MF, Ferreira MC, Altemani A, Mamoni RL, Menezes FH, Blotta MH: Detection of TCD4+ subsets in human carotid atheroma. Cytokine, 2013; 62: 131-140

29) Erbel C, Dengler TJ, Wangler S, Lasitschka F, Bea F, Wambsganss N, Hakimi M, Böckler D, Katus HA, Gleissner CA: Expression of IL-17A in human atherosclerotic lesions is associated with increased inflammation and plaque vulnerability. Basic Res Cardiol, 2011; 106: 125134

30) Del Porto F, Cifani N, Proietta M, Perrotta S, Dito R, di Gioia C, Carletti R, Rizzo L, Orgera G, Rossi M, Ferri L, Tritapepe L, Taurino M: Regulatory T CD4+ CD25+ lymphocytes increase in symptomatic carotid artery stenosis. Ann Med, 49: 283-290

31) Arslan C, Bayoglu B, Tel C, Cengiz M, Dirican A, Besirli K: Upregulation of OLR1 and IL17A genes and their association with blood glucose and lipid levels in femoropopliteal artery disease. Exp Ther Med, 2017; 13: 11601168

32) Taleb S, Romain M, Ramkhelawon B, Uyttenhove C, Pasterkamp G, Herbin O, Esposito B, Perez N, Yasukawa $\mathrm{H}$, Van Snick J, Yoshimura A, Tedgui A, Mallat Z: Loss of SOCS3 expression in $T$ cells reveals a regulatory role for interleukin-17 in atherosclerosis. J Exp Med, 2009; 206: 2067-2077

33) Liu Z, Lu F, Pan H, Zhao Y, Wang S, Sun S, Li J, Hu X, Wang L: Correlation of peripheral Th17 cells and Th17associated cytokines to the severity of carotid artery plaque and its clinical implication. Atherosclerosis, 2012; 221: 232-241

34) Cheng X, Yu X, Ding YJ, Fu QQ, Xie JJ, Tang TT, Yao R, Chen Y, Liao YH: The Th17/Treg imbalance in patients with acute coronary syndrome. Clin Immunol, 2008; 127: 89-97

35) Zhu F, Wang Q, Guo C, Wang X, Cao X, Shi Y, Gao F, Ma C, Zhang L: IL-17 induces apoptosis of vascular endothelial cells: a potential mechanism for human acute coronary syndrome. Clin Immunol, 2011; 141: 152-160

36) Li Q, Wang Y, Chen K, Zhou Q, Wei W, Wang Y, Wang Y: The role of oxidized low-density lipoprotein in breaking peripheral Th17/Treg balance in patients with acute coronary syndrome. Biochem Biophys Res Commun, 2010; 394: 836-842

37) Potekhina AV, Pylaeva E, Provatorov S, Ruleva N, Masenko V, Noeva E, Krasnikova T, Arefieva T: Treg/ 
Th17 balance in stable CAD patients with different stages of coronary atherosclerosis. Atherosclerosis, 2015; 238: $17-21$

38) de Boer OJ, van der Meer JJ, Teeling P, van der Loos CM, Idu MM, van Maldegem F, Aten J, van der Wal AC: Differential expression of interleukin-17 family cytokines in intact and complicated human atherosclerotic plaques. J Pathol, 2010; 220: 499-508

39) Kim JD, Lee SH, Seo EH, Woo SY, Kim SH, Chung SM, Kim HJ: Role of Th1 and Th17 cells in the development and complexity of coronary artery disease: comparison analysis by the methods of flow cytometry and SYNTAX score. Coron Artery Dis, 2015; 26: 604-611

40) Simon T, Taleb S, Danchin N, Laurans L, Rousseau B, Cattan S, Montely JM, Dubourg O, Tedgui A, Kotti S, Mallat Z: Circulating levels of interleukin-17 and cardiovascular outcomes in patients with acute myocardial infarction. Eur Heart J, 2013; 34: 570-577

41) Yu XH, Jiang N, Zheng XL, Cayabyab FS, Tang ZB, Tang $\mathrm{CK}$ : Interleukin-17A in lipid metabolism and atherosclerosis. Clin Chim Acta, 2014; 431: 33-39

42) Gong F, Liu Z, Liu J, Zhou P, Liu Y, Lu X: The paradoxical role of IL-17 in atherosclerosis. Cell Immunol, 2015; 297: 33-39 
Wu et al.

Supplementary Table 1. SNPs within $25 \mathrm{~Kb}$ up- and down-stream of the $I L-17$ genes in the discovery study

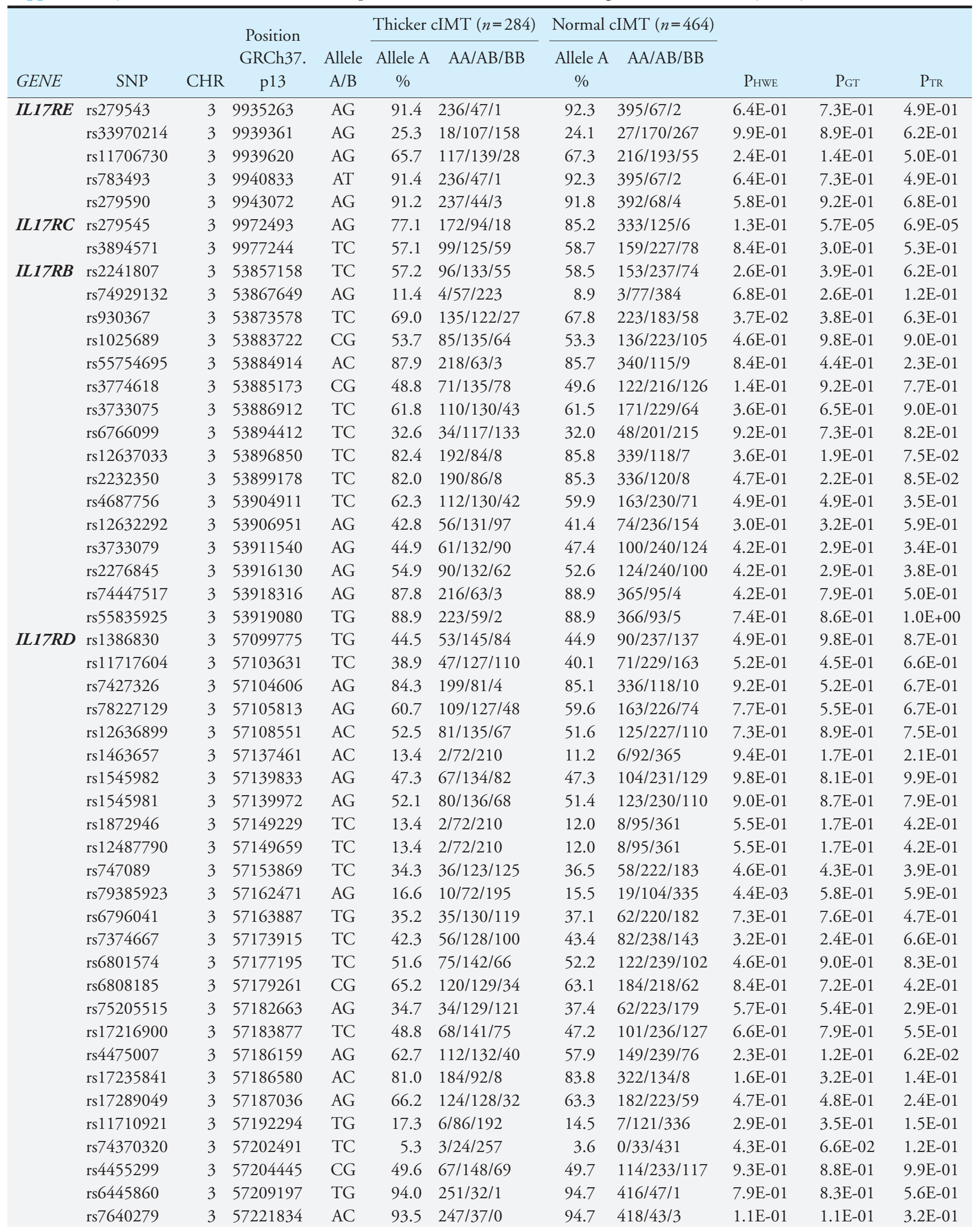


(Cont Supplementary Table 1)

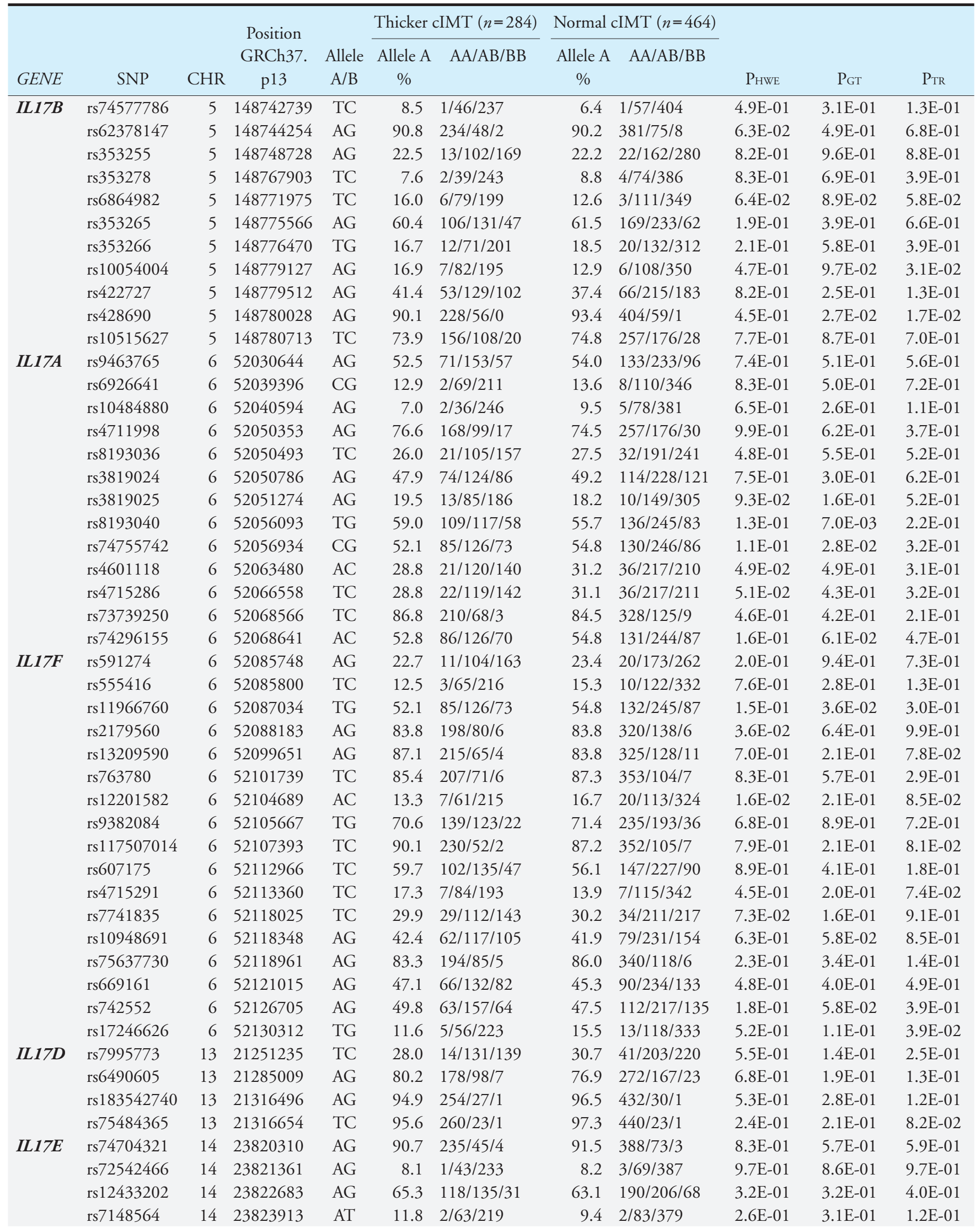


Wu et al.

(Cont Supplementary Table 1)

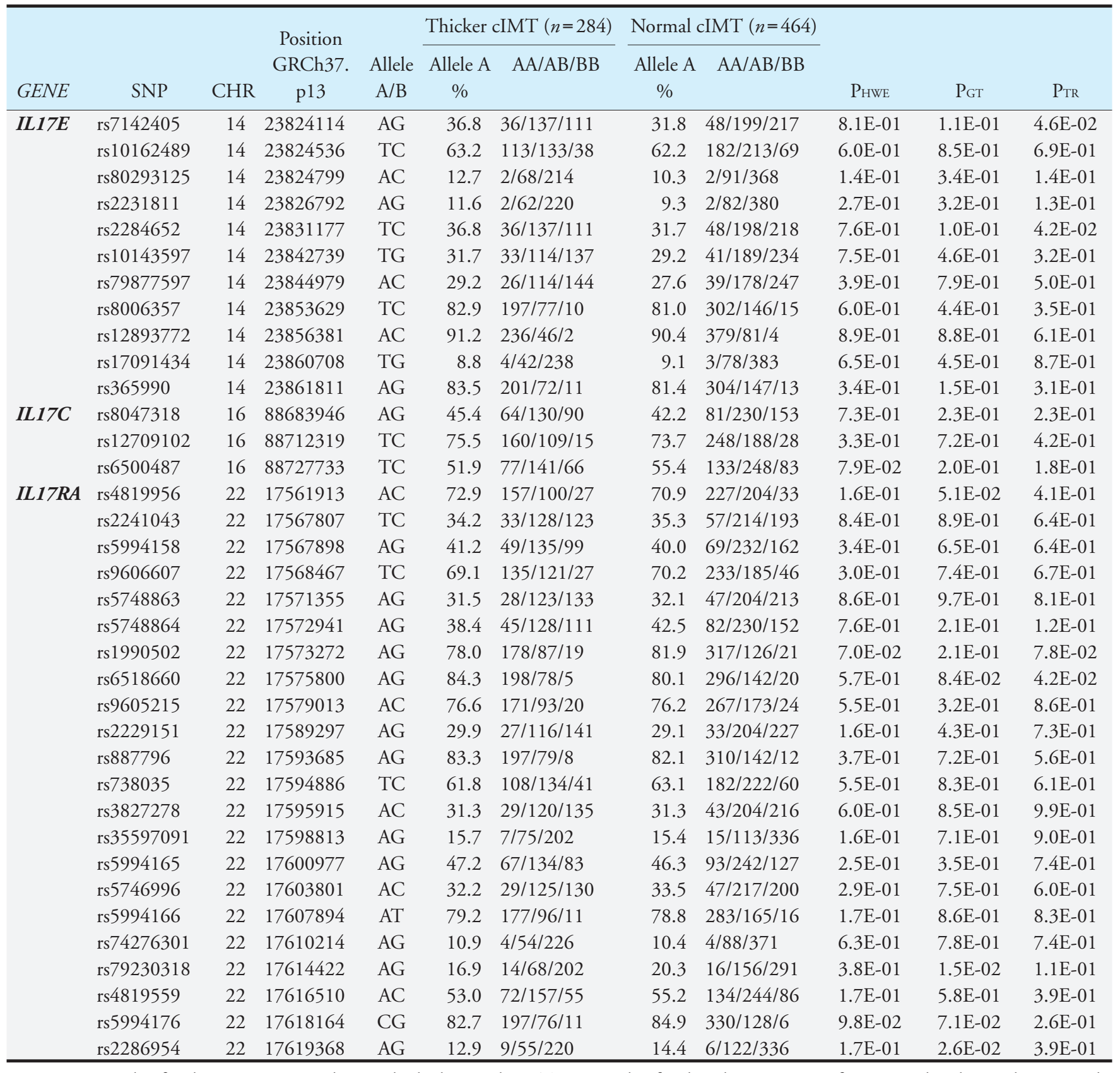

Note: PHWE, $p$-value for the HWE test in subjects who had normal cIMT; PGT, $p$-value for the Chi-square test of genotype distribution between subjects who had thicker and normal cIMT; PтR: $p$-value for the additive genotypic model. 
Supplementary Table 2. Details of the primers used in the polymorphism genotyping by MassArray

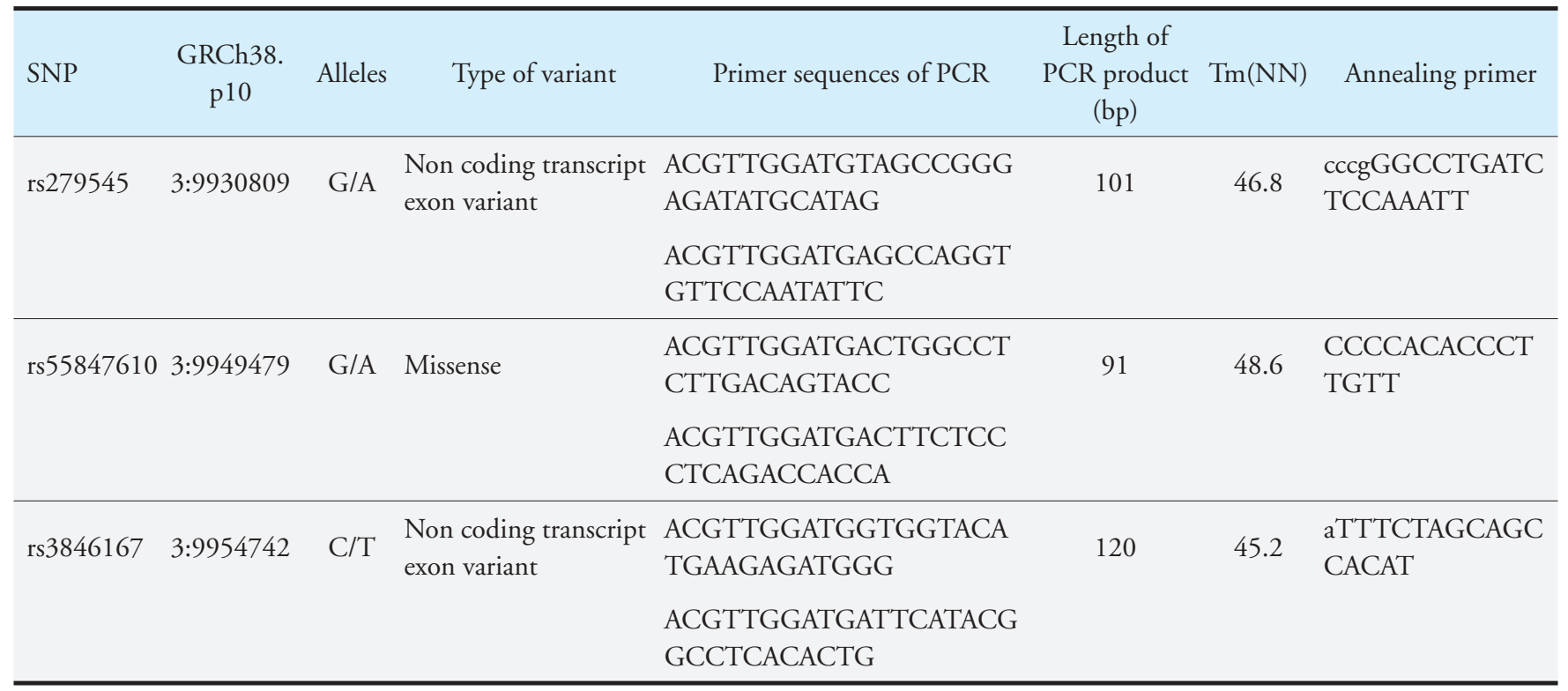

